\title{
Aún tenemos que aprender sobre terapia transfusional.
}

La transfusión sanguínea ha cumplido un rol terapéutico muy importante en la práctica médica, con beneficios obvios para quien lo necesita, pero con una serie de riesgos y consecuencias que obligan a plantear pautas para su uso. Por otro lado esta práctica terapéutica nos deja una serie de preguntas para las cuales debemos buscar respuestas.

En el siglo XVII se practicaron las primeras transfusiones entre animales, con indicaciones básicamente experimentales, mas no con motivaciones terapéuticas. El éxito de las mismas planteó la idea de transfundir sangre de animal a hombre, lo que ocasionó muchas muertes y complicaciones, por lo que esta práctica fue suspendida hacia el año 1680. La hemólisis como causa de muerte en transfusiones sanguíneas de hombre a hombre, ya descrita a finales del siglo XIX, encuentra respuesta parcial en 1901 cuando Landsteimer comienza a descubrir la existencia de grupos sanguíneos y no es hasta 1940 en que Wiener describe el sistema Rhesus, en que se plantea la terapia sanguínea como una practica con "seguridad completa".

La experiencia en diferentes disciplinas de la ciencia, pero en especial la médica nos enseña a ser cautos, y a entender la limitación y temporalidad de frases como esta.

Los años que siguieron al inicio del uso habitual en la práctica médica de transfusiones sanguíneas mostraron la existencia de otros eventos adversos, y dejaron claro que no todos los riesgos estaban controlados. Se describieron enfermedades que podían ser transmitidas a través de la sangre, entre ellas Sífilis, Malaria, Trypanosomiasis, Hepatitis B. Algunas de ellas como malaria afecta extensas áreas del planeta y son un problema en los Bancos de Sangre. El plasmodium ocasiona en el sujeto transfundido un proceso agudo de severidad variada, existiendo a la fecha algunas alternativas de terapia medicamentosas, pero que lamentablemente están viéndose limitadas por el problema de emergencia de resistencia.

Otras enfermedades como Hepatitis B y Trypanosomiasis Americana (Enfermedad de Chagas), pueden causar procesos crónicos de alta morbilidad, para los cuales no existen buenas alternativas terapéuticas y que pueden llevar al sujeto en forma progresiva a la inhabilidad y luego a la muerte. Otras, como la Hepatitis por virus Delta o la Fiebre Amarilla pueden ocasionar al sujeto la muerte por hepatitis fulminante. Cada vez se descubren nuevas enfermedades transmitidas por sangre como lo son Virus de Hepatitis $\mathrm{C}$ que tiene una alta chance de causar hepatitis crónica en el sujeto; El HTLV1 agente causal de Paraparesia Espástica Tropical, y de Leucemia y Linfoma a Células T; y el VIH agente causal una de las epidemias de mayor impacto en la Humanidad.

Que nos falta conocer? Obviamente en un futuro descubriremos que agentes causales (no conocidos actualmente), de viejas enfermedades conocidas actualmente se transmiten de esta manera. Descubriremos también que estructuras más precarias como priones u vehículos de transmisión de material genético pueden también ser transmitidos de esta forma.

Los avances en los últimos años no solo se han dado en el área de descubrir que problemas complican el uso de productos sanguíneos. También se han descubierto alternativas que hacen algo más seguro la terapia transfusional, 
entre las que se encuentran alternativas muy interesantes como lo son la transfusión sustancias alternativas a los productos sanguíneos u otras mas sencillas a considerar como la autotransfusión.

El artículo que se publica en este número de la revista cuyo autor principal es el Dr. De la Cruz Del Solar, nos describe cual es la prevalencia de infecciones como Sífilis, Hepatitis y VIH en los donantes de sangre que acudieron al Banco de Sangre del Hospital Nacional Cayetano Heredia. La información obtenida en este estudio es de gran utilidad por varias razones: en primer lugar nos advierte de la magnitud del riesgo por estas enfermedades de la población receptora, lo cual nos obliga a ser cautos y responsables en la decisión de transfundir a un sujeto y también nos obliga a programar actividades preventivas con la finalidad de disminuir los riesgos inherentes a la terapia transfusional. En segundo lugar, al contrastar sus resultados con los de otros estudios, nos muestran el incremento de las cifras a lo largo del tiempo, y la variabilidad de las cifras en las diferentes regiones e Instituciones, lo cual nos lleva a concluir que las cifras son variables y relativas, lo que obliga a generar un sistema de vigilancia con redes interinstitucionales, interregionales, con procesos estandarizados y con la garantía de continuidad a lo largo del tiempo.

Actualmente la adquisición de conocimientos está en un crecimiento exponencial. Sin embargo, por otro lado se cumple la regla que dice que cuanto más conozcamos acerca de un tópico, mas cuenta nos daremos de que nos falta mucho por conocer y eso se hace notorio en el conocimiento actual sobre terapia transfusional.

Dr. Juan Echevarría *

* $\quad$ Profesor de Medicina de la Universidad Peruana Cayetano Heredia. 